\title{
Government Low-Carbon Regulations Based on Supply Chain Members' Behavior and Consumers' Channel Preference in a Dual-Channel Supply Chain
}

\author{
Bingquan Liu ${ }^{1}$, ${ }^{1,2}$ Xuran Chang, ${ }^{1}$ Boyang Nie, ${ }^{1}$ Yue Wang, ${ }^{1}$ and Lingqi Meng ${ }^{1}$ \\ ${ }^{1}$ School of Economics \& Management, China University of Petroleum (East China), Qingdao 266580, Shandong, China \\ ${ }^{2}$ Institute for Energy Economics and Policy, China University of Petroleum (East China), Qingdao 266580, Shandong, China \\ Correspondence should be addressed to Bingquan Liu; liubq@upc.edu.cn
}

Received 31 March 2021; Accepted 20 May 2021; Published 1 June 2021

Academic Editor: Baogui Xin

Copyright ( $) 2021$ Bingquan Liu et al. This is an open access article distributed under the Creative Commons Attribution License, which permits unrestricted use, distribution, and reproduction in any medium, provided the original work is properly cited.

\begin{abstract}
As carbon emissions are increasing due to the development of economy, low-carbon supply chain plays an important role in carbon emissions reduction and the dual-channel supply chain has become a hit because online shopping is developing rapidly. Therefore, this paper builds a Stackelberg game model led by the manufacturer in a dual-channel supply chain to examine the reaction of the government under centralized or decentralized decisions-making structures with different low-carbon strategies. The result shows that the government can achieve higher profits by taking incentive or punitive measures for centralized decisionmaking supply chain no matter they invest in emissions reduction or not. Moreover, for decentralized decision-making mode, increasing low-carbon subsidies for retailers can achieve a win-win result between the supply chain and the government; and, finally, channel competition is good for improving the supply chain and social benefits. Therefore, the government is responsible for taking reasonable subsidy policies, formulate industry's low-carbon standards, and properly guide competition between supply chain members to achieve higher profits.
\end{abstract}

\section{Introduction}

Recently, climate change has become a major challenge for countries across the world [1,2]. Some developed countries pay more attention to low-carbon economy by formulating administrative intervention policies and promulgating laws and regulations. For example, some western countries, like Sweden, Norway, Finland, Denmark, and so on, levy carbon taxes to control carbon emissions of companies [3]. As the largest $\mathrm{CO}_{2}$ emitter, China has pledged to control its $\mathrm{CO}_{2}$ emissions as a binding development and economic target at the Paris Climate Conference in 2015 [4], setting a target to peak emissions before 2030 and become carbon-neutral before 2060. To achieve the emission reduction goals, the government has initiated regulations to promote low-carbon supply chain and control the carbon emissions consequently.

With the development of mobile Internet, online shopping is becoming more popular in China than before. In
2020, the number of online shopping consumers reached 782 million, accounting for $79.1 \%$ of the total netizens. At the same time, the amount of online retail sales has also maintained rapid growth, with 11.76 trillion yuan, an increase of $10.9 \%$ over 2019 . Therefore, manufactures can provide products to customers directly with online channel and can react to their preference quickly. Thus, many manufacturers, such as Interface and GREE, decide to sell products in both traditional retail channels (offline channels) and direct sales channels (online channels) to improve their competitiveness, which is defined as the dual-channel supply chain. In this supply chain, manufacturers are not only retailer's suppliers but also their competitors. However, when they cooperate, they are partners to bear carbon reduction costs together. Thus, while enhancing distribution channels, companies should also consider the impact of decision-making methods among supply chain members on emission reduction costs. Facing with different decision- 
making modes among supply chain members and emission reduction strategies of them, governments will take different measures to motivate or punish these supply chain node companies, which is bound to affect the optimal profit of supply chain members and social profits. Therefore, studying the effect of government regulations with different decisionmaking modes and low-carbon strategies is meaningful to reduce carbon emissions and maximize the profit of all parties. Moreover, dual channels have changed consumers' channel preference obviously, because online direct sales channels have convenience and low-cost advantages. Therefore, consumers' channel preference is also significant for the profit of supply chain members and the government.

In this paper, we construct a Stackelberg game model between a manufacturer as the leader and a retailer as the follower in a dual-channel supply chain, where one manufacturer has both traditional retailer channel and direct sales channel. Meanwhile, the manufacturer decides whether to invest in emissions reduction under centralized and decentralized decision-making model, respectively. If they make centralized decisions, they are regarded as a whole to share benefits and risks from the government; otherwise, they will bear each part of the benefits and risks from the government. The government has two regulation strategies, providing subsidies when companies have emission reduction investment and charging fines when they do not have emission reduction costs.

Then the optimal price decisions and the profits of supply chain members and the government's utility are given among these four models, which is the basic of governmental low-carbon regulations for the supply chain. This paper aims to explore the following questions: (1) What are the impacts of government subsidies and consumer preferences on each supply chain member's profit and social benefits? (2) How does the government formulate appropriate low-carbon regulatory strategies based on the lowcarbon decisions of enterprises?

The rest of this paper is organized as follows. Section 2 summarizes the literature review. Section 3 presents the description and assumptions of the model. Section 4 and Section 5 are main parts of this paper: the former shows four models based on two decision-making modes under different carbon reduction strategies and theoretical analysis, and the latter gives further numerical analysis to clarify theoretical results. Then Section 6 concludes this study.

\section{Literature Review}

Carbon emissions have become a commonly important issue around the world, and many scholars are interested in lowcarbon supply chains. As for low-carbon supply chain researches, they can be divided into two kinds of supply chain, single-channel supply chain and dual-channel supply chain. In single-channel supply chain researches, Ghosh and Shah [5] studied coordination problems among members in a single-channel supply chain and explored the impact of costsharing contract on the key decisions of supply chain players undertaking green initiatives. Du et al. [6] focused on the supply chain consisting of one single emission-dependent manufacturer and one single emission permit supplier in the "cap-and-trade" system and found that the system-wide and manufacturer's profits increase with the emission cap, while the supplier's permit decreases. Besides, Xu et al. [7] also explored the impact of carbon allowances and transaction supervision on production and emission reduction strategies in a single-channel supply chain. However, with the rapid development of e-commerce, the scale of online sales has shown a sharp growth in recent years. Since then, the dualchannel supply chain in which online direct sales channels coexist with traditional retail channels has become the main distribution model for manufacturers.

At present, a number of studies about dual-channel supply chain mainly focus on pricing strategy $[8,9]$, channel coordination $[10,11]$, and carbon reduction strategy $[12,13]$. The most extensive research has been done in the stream of pricing strategy. Some examples are listed as follows. Barman et al. [14] constructed a dual-channel supply chain, containing a manufacturer and a retailer, in which the manufacturer has sold the product through the online channel along with the traditional retail channel to optimize the pricing decisions and maximize the profit. Zhang et al. [15] investigated a dynamic pricing strategy and greening issues for a two-stage dual-channel supply chain and found that reviewing price periodically is able to enlarge supply chain profits and market demands. Zhou et al. [16] and Li et al. [17] also studied the pricing decisions using the Stackelberg game model.

With regard to channel coordination, it is formed on the basis of centralized decision-making and decentralized decision-making patterns. Contracts can equal the optimal decision of the decentralized supply chain and that of the centralized supply chain, which also means that supply chain coordination and pareto improvement in profits can be obtained by contracts. Popular supply chain contracts that have been designed in the literature include price discount contract $[18,19]$, quantity discount contract $[20,21]$, revenue-sharing contract $[22,23]$, cost-sharing contract $[24,25]$, wholesale price contract $[26,27]$, and option contract $[28,29]$. Cai et al. [19] introduced price discount contracts into the dual-channel supply chain and proved that the cases with price discount contracts can outperform the noncontract cases from supplier Stackelberg, retailer Stackelberg, and Nash game theoretic perspectives. Xie and Huang [20] established a quantity discount model and pointed out that both members in the mixed-channel supply chain can achieve a win-win situation by adjusting the quantity discount rate. $\mathrm{Xu}$ et al. [22] proposed a two-way revenue-sharing contract not only to coordinate the dualchannel supply chain but also to create a win-win situation among supply chain members. Moreover, cost-sharing contracts have been widely used as an effective mechanism to encourage supply chain coordination, which is also highly related to our study [30]. Wang et al. [31] established single and joint emission reduction models with one-way or twoway cost-sharing contracts. They found that the implementation of contracts is beneficial to the increase of carbon emission abatement level and product quantity as well as supply chain profit. Particularly, the two-way cost-sharing 
contract is positive for supply chain when the sharing rate is in a small range. This model also offers better performance in extended multiple retailers' mode.

Besides, the carbon reduction strategy has also been quite popular recently. Some papers discussed the emission reduction decisions of corporates. For example, Sarkar et al. [32] established a three-echelon supply chain model to reduce supply chain costs, considering variable and fixed carbon emissions when transporting products; Li et al. [33] studied the optimal decision-making of the supply chain, including a manufacturer and two competing retailers, for vertical and horizontal cooperation in emission reduction; Aljazzar et al. [34] considered delayed payment, transportation costs, and carbon emission costs to study various situations in which buyers delay payment after receiving items. However, emission reduction is closely related to the government and enterprises, so it is necessary for the government to formulate reasonable and effective regulations to promote carbon reduction in enterprises [35]. There are many ways of government regulations, including subsidies and fines [36], carbon taxes [37], quotas [38], and carbon transactions [6]. Wu [39] examined the effect of different types of government intervention, including a fixed tax or subsidy on the firm side, a unit tax or subsidy on the firm side, and a unit tax or subsidy on the consumer side. Except for the policy with the fixed subsidy to the independent remanufacturer, the proposed policies can reduce the environmental burden and mitigate the intensity of price competition effectively. Zhang et al. [40] examined progressive carbon tax mechanism and its impacts on the production/pricing and abatement level decisions of the manufacturers as well as the influences of the online channel introduction on supply chain network equilibrium decisions, carbon emissions, and profits. Meanwhile, consumers' channel preferences also affect pricing decisions in the case of dual-channel sales coexistence. Zhang and Hezarkhani [41] studied the effect of consumers' channel preferences on channel strategies. Tian et al. [42] found that a great adjustment of supply order quantity in direct channels, retailer's order quantity, consumers' channel preference, and sales effort will cause the system to lose stability and trap into complexity. Meng et al. [43] proposed a green dual-channel supply chain considering consumer green preference and channel preference and compared the optimal solutions with or without government subsidies. Their results show that government subsidies are beneficial to the manufacturer, and the impact on retailer's profit depends on the amount of government subsidies.

In general, previous literature has made great contributions to the knowledge of supply chains, but there are still some gaps shown as follows: First, online shopping has changed the competitive relationship between manufacturers and retailers, so fierce competition exists between traditional retail channel and direct sales channel. Simultaneously, online channel has propelled carbon emissions during the process of transportation. However, to the best of our knowledge, there are relatively few studies exploring low-carbon strategies in dual-channel supply chain, so it will be scientific to study low-carbon strategies in different channels. Second, previous studies generally studied how supply chain members are affected by different government regulations. Actually, governments also need to adjust their own low-carbon regulations according to supply chain members' low-carbon decisions, so it is meaningful to explore how the governments react when companies make different low-carbon decisions. Furthermore, most of existing articles simply analyzed the effect of single parameter, such as the cross-price elasticity coefficient of the alternative channel and the level of emission reduction, but only a few articles focus on government regulations and consumers' channel preference. Actually, government and consumers are two main bodies to affect the profits of the supply chain, so the change of them has an uncertain impact on the profit of all members and social benefits.

Compared with existing research, the main contributions of this paper are given as follows. First, this paper studied low-carbon strategies in a dual-channel supply chain, where there exist a traditional retail channel and an online direct sale channel, which is more realistic as online direct sale channel is significant to reduce carbon emissions during the processes of production, transportation, and distribution; and the change of prices in different sales channel is able to influence the overall profits of manufacturers and retailers. Second, different from previous research, this paper is from the perspective of the government rather than supply chain members to study what the government should do to achieve optimal social benefits and supply chain profits facing different companies' low-carbon emissions strategies, which could provide more practicality and specific details for the government to regulate carbon emissions. Third, this paper studied the effect of the supply chain members' low-carbon behavior and consumers' retail channel preference on the profits of the supply chain and social profits, which is more comprehensive to show how the government guides the competition between different channels.

\section{Description of the Problem}

3.1. Model Description. This paper builds a two-echelon dual-channel supply chain system consisting of a manufacturer and a retailer. The manufacturer sells products not only through traditional retail channels but also through online direct sale channels, so they need to determine both the wholesale price $w$ and the direct sale price pe to the retailer and consumers, respectively, while the retailer only needs to decide the retail price pr based on market demand. In addition, because the asymmetry of information often exists between competitors and the manufacturer has strong economic strength, the manufacturer is generally assumed to dominate the model, and the retailer is a subsidiary in the decision-making process. Therefore, this paper builds a Stackelberg game to show the symmetry in decision-making, which is more realistic. Besides, the government provides low-carbon subsidies as incentive measures when companies invest in carbon emissions reduction and charges fines as punitive measures when they do not do so. The structure of the dual-channel sales supply chain is shown in Figure 1. 


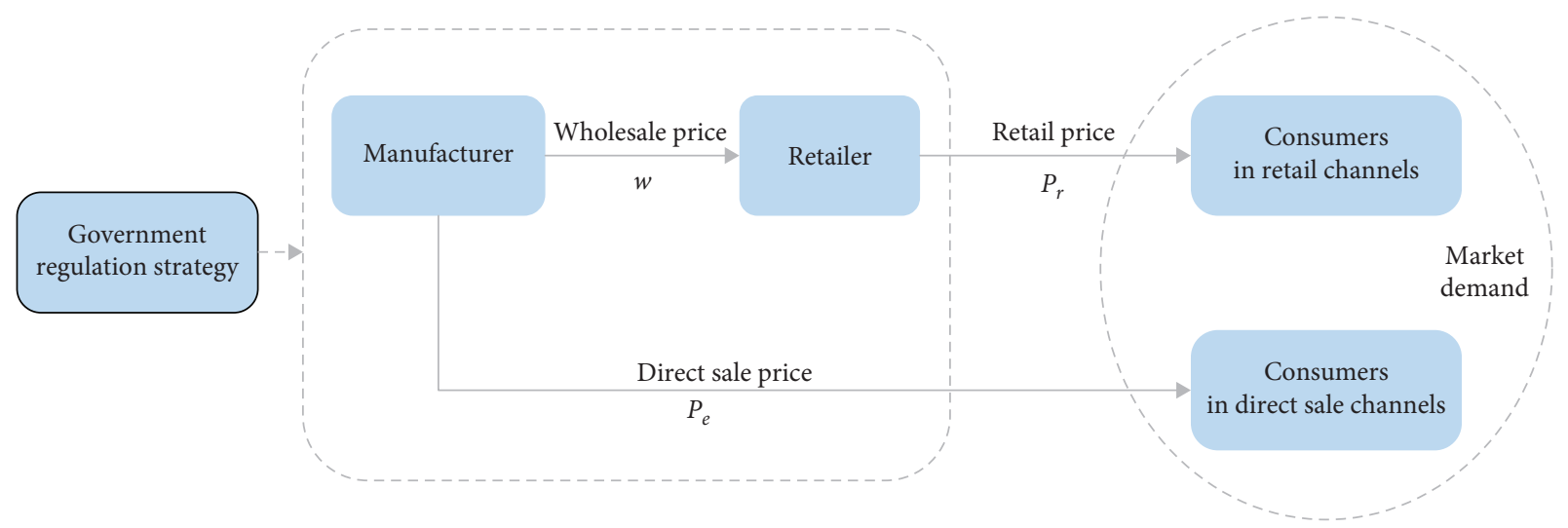

FIgURE 1: Dual-channel supply chain structure.

3.2. Notation and Assumption. The notations and the symbolic descriptions of the model are summarized in Table 1.

To simplify the research, the following are the necessary assumptions for the model:

(1) Assume that the manufacturer is the leader and the retailer is the follower; both are risk-neutral and seek to maximize their own profits.

(2) In order to simplify the calculation, the production cost is neglected, and there is no inventory cost as this paper assumes that the retailer's order quantity is the same as the demand function.

(3) Considering the fact that the higher the carbon emission reduction level is, the higher the corresponding cost is, the cost of emission reduction function can be assumed as a convex function about the emission reduction level $\theta$, which is shown as follows:

$$
I(\theta)=\frac{1}{2} \mu \theta^{2}
$$

where $\mu>0$, representing the manufacturer's cost elasticity coefficient of emission reduction; and, according to cost-sharing contract [31], assume that the manufacturer invests in reducing emissions, and the retailer bears a certain percentage of emission reduction costs.

(4) The demand function of the channel in the dualchannel supply chain is affected by the price of its own channel and that of the alternative channel. From [22], we consider the demand function to be the linear function with respect to the sales prices, which is constructed as

$$
\begin{aligned}
& q_{r}=\rho a-\beta p_{r}+r p_{e} \\
& q_{e}=(1-\rho) a-\beta p_{e}+r p_{r} .
\end{aligned}
$$

In the above equation, $a$ is a constant indicating the total of market demand; $\rho(0<\rho<1)$ indicates the degree of
TABLE 1: The description of the symbols.

\begin{tabular}{lc}
\hline Notation & Description \\
\hline$p_{r}$ & The per unit retail price \\
$p_{e}$ & The per unit direct sales price \\
$w$ & The per unit wholesale price \\
$\Pi_{M}$ & The profit of the manufacturer \\
$\Pi_{R}$ & The profit of the retailer \\
$\Pi_{S C}$ & The profit of the total supply chain \\
$\Pi_{G}$ & The utility of the government \\
$a$ & The potential market demand \\
$\rho$ & The degree of consumer preference for the retail \\
$r$ & channel \\
$\beta$ & The cross-price elasticity coefficient of the alternative \\
$\theta$ & The price elasticity coefficient \\
$\mu$ & The level of emission reduction \\
$\lambda$ & The cost elasticity coefficient of emission reduction. \\
$s$ & The proportion of emission reduction costs \\
$m$ & The government's subsidy coefficient \\
\hline
\end{tabular}

consumer preference for the retail channel; $r$ indicates the cross-price elasticity coefficient of the alternative channel. Since the price of the own channel has a greater influence on the demand than that of the alternative channel, the range of $r$ is between 0 and 1 . In order to simplify the calculation, suppose that the price elasticity coefficient of the own channel $\beta$ is 1 .

\section{Model Solution and Analysis}

In this section, we consider two decision-making modes among supply chain members. One is centralized decisionmaking of the entire supply chain, and the other is decentralized decision-making of the manufacturer and the retailer independently. In each mode, the game model between supply chain members and the utility of government model is established under two different low-carbon decisions by the manufacturer and expected to find the equilibrium solution to promote better emission reduction decision-making by all parties. 


\subsection{Manufacturers' Emission Reduction Investment Model}

4.1.1. Centralized Decision. When the manufacturer and the retailer make centralized decisions, they consider the overall profit of the supply chain. At this time, the unit subsidy given by the government is $s$, and the total profit function of the supply chain is

$$
\pi_{S C}^{Y C}=\left(p_{r}+s \theta\right)\left(\rho a-p_{r}+r p_{e}\right)+\left(p_{e}+s \theta\right)\left((1-\rho) a-p_{e}+r p_{r}\right)-\frac{1}{2} \mu \theta^{2} .
$$

From (3), the Hessian matrix of $\pi_{S C}^{Y C}$ with $p_{r}$ and $p_{e}$ is $H^{Y C}=\left[\begin{array}{cc}-2 & 2 r \\ 2 r & -2\end{array}\right]$. According to assumption (4), the range of $r$ is between 0 and 1 ; then $\left|H_{1}^{Y C}\right|=-2<0$ and $\left|H_{2}^{Y C}\right|=4\left(1-r^{2}\right)>0$, so $H^{Y C}$ is a negative definite matrix. It means that the total profit function of the supply chain is concave with respect to $p_{r}$ and $p_{e}$ and there exists a maximum.

From (3), the first-order derivatives of $p_{r}$ and $p_{e}$ are

$$
\left\{\begin{array}{l}
\frac{\partial \pi_{S C}^{Y C}}{\partial p_{r}}=\rho a-2 p_{r}+2 r p_{e}-(1-r) s \theta=0, \\
\frac{\partial \pi_{S C}^{Y C}}{\partial p_{e}}=(1-\rho) a-2 p_{e}+2 r p_{r}-(1-r) s \theta=0 .
\end{array}\right.
$$

The optimal retail price and direct sales price are shown as follows:

$$
\begin{aligned}
& p_{r}^{Y C}=\frac{(\rho+r-\rho r) a-\left(1-r^{2}\right) s \theta}{2\left(1-r^{2}\right)}, \\
& p_{e}^{Y C}=\frac{(1-\rho+\rho r) a-\left(1-r^{2}\right) s \theta}{2\left(1-r^{2}\right)} .
\end{aligned}
$$

Taking (5) and (6) into (3), the total profit of the supply chain is

$$
\pi_{S C}^{Y C}=\frac{(1-2 \rho(1-\rho)(1-r)) a^{2}+2 s \theta\left(1-r^{2}\right) a+2 s^{2} \theta^{2}(1-r)\left(1-r^{2}\right)}{4\left(1-r^{2}\right)}-\frac{1}{2} \mu \theta^{2},
$$

and the utility of the government is

$$
\pi_{G}^{Y C}=\pi_{S C}^{Y C}-s \theta\left(q_{r}+q_{e}\right)=\frac{(1-2 \rho(1-\rho)(1-r)) a^{2}-2 s^{2} \theta^{2}(1-r)\left(1-r^{2}\right)}{4\left(1-r^{2}\right)}-\frac{1}{2} \mu \theta^{2} .
$$

4.1.2. Decentralized Decision. When the manufacturer and the retailer make decentralized decisions, the per unit products of subsidies given by the government to encourage the manufacturer and the retailer to reduce emissions are $s_{1}$ and $s_{2}$, respectively. The following are the profit functions of the manufacturer and the retailer:

$$
\begin{gathered}
\pi_{M}^{Y D}=\left(w+s_{1} \theta\right)\left(\rho a-p_{r}+r p_{e}\right)+\left(p_{e}+s_{1} \theta\right)\left((1-\rho) a-p_{e}+r p_{r}\right)-\frac{1}{2}(1-\lambda) \mu \theta^{2} \\
\pi_{R}^{Y D}=\left(p_{r}-w+s_{2} \theta\right)\left(\rho a-p_{r}+r p_{e}\right)-\frac{1}{2} \lambda \mu \theta^{2} .
\end{gathered}
$$

According to Stackelberg game theory, the manufacturer, as the leader in the supply chain, determines the wholesale price $w$ and the direct sales price $p_{e}$ at first, and then the retailer determines the retail price $p_{r}$ as the follower. Based on the converse approach, the retailer's objective function is 
$\max _{p_{r}} \pi_{R}^{Y D}=\left(p_{r}-w+s_{2} \theta\right)\left(\rho a-p_{r}+r p_{e}\right)-\frac{1}{2} \lambda \mu \theta^{2}$,

and, from (11), the optimal retail price of the retailer is

$$
p_{r}^{Y D}=\frac{\rho a+w+r p_{e}-s_{2} \theta}{2} .
$$

Taking (12) into (9), the manufacturer's objective function is

$$
\max _{p_{e}, w} \pi_{M}^{Y D}=\left(w+s_{1} \theta\right)\left(\frac{\rho a-w+r p_{e}+s_{2} \theta}{2}\right)+\left(p_{e}+s_{1} \theta\right)\left((1-\rho) a-p_{e}+r\left(\frac{\rho a+w+r p_{e}-s_{2} \theta}{2}\right)\right)-\frac{1}{2}(1-\lambda) \mu \theta^{2}
$$

Obviously, $\pi_{M}^{Y D}$ is a joint strictly concave function with $p_{e}$ and $w$. According to its first-order derivative, the optimal wholesale price and direct sales price are shown as follows:

$$
\begin{gathered}
w^{Y D}=\frac{(\rho+(1-\rho) r) a-\left(1-r^{2}\right) s_{1} \theta+\left(1-r^{2}\right) s_{2} \theta}{2\left(1-r^{2}\right)}, \\
p_{e}^{Y D}=\frac{(1-\rho+\rho r) a-\left(1-r^{2}\right) s_{1} \theta}{2\left(1-r^{2}\right)} .
\end{gathered}
$$

Taking (14) and (15) into (12), the optimal retail price can be calculated as

$$
p_{r}^{Y D}=\frac{(3 \rho+(2(1-\rho)-\rho r) r) a-\left(1-r^{2}\right)(1+r) s_{1} \theta-\left(1-r^{2}\right) s_{2} \theta}{4\left(1-r^{2}\right)} .
$$

Then, taking (14)-(16) into (9) and (10), the profits of the manufacturer and the retailer are shown, respectively, as follows:

$$
\begin{aligned}
& \pi_{M}^{Y D}=\frac{\left(2-4 \rho(1-r)+\rho^{2}(1-r)(3-r)\right) a^{2}-2 s_{1} \theta a\left(1-r^{2}\right)(2-\rho(1-r))+2 \rho s_{2} \theta a\left(1-r^{2}\right)+\left(1-r^{2}\right)(1-r)(3+r) s_{1}^{2} \theta^{2}+2\left(1-r^{2}\right)(1-r) s_{1} s_{2} \theta^{2}+\left(1-r^{2}\right) s_{2}^{2} \theta^{2}}{8\left(1-r^{2}\right)}-\frac{1}{2}(1-\lambda) \mu \theta^{2} \\
& \pi_{R}^{Y D}=\frac{\left(\rho a+(1-r) s_{1} \theta+s_{2} \theta\right)^{2}}{16}-\frac{1}{2} \lambda \mu \theta^{2} .
\end{aligned}
$$

Therefore, the following are the total profit of the supply chain and the utility of the government sequentially:

$$
\begin{aligned}
& \pi_{S C}^{Y D}=\frac{\left(4-8 \rho(1-r)+\rho^{2}(1-r)(7-r)\right) a^{2}+s_{1} \theta a\left(1-r^{2}\right)(6 \rho(1-r)-8)+6 \rho s_{2} \theta a\left(1-r^{2}\right)+\left(1-r^{2}\right)(1-r)(7+r) s_{1}^{2} \theta^{2}+6\left(1-r^{2}\right)(1-r) s_{1} s_{2} \theta^{2}+3\left(1-r^{2}\right) s_{2}^{2} \theta^{2}}{16\left(1-r^{2}\right)}-\frac{1}{2} \mu \theta^{2}, \\
& \pi_{G}^{Y D}=\frac{\left(4-8 \rho(1-r)+\rho^{2}(1-r)(7-r)\right) a^{2}+2 s_{1} \theta a\left(1-r^{2}\right)(5 \rho(1-r)-8)+2 \rho s_{2} \theta a\left(1-r^{2}\right)-\left(1-r^{2}\right)(1-r)(3 r+5) s_{1}^{2} \theta^{2}-2\left(1-r^{2}\right)(1-r) s_{1} s_{2} \theta^{2}-\left(1-r^{2}\right) s_{2}^{2} \theta^{2}}{16\left(1-r^{2}\right)}-\frac{1}{2} \mu \theta^{2} .
\end{aligned}
$$

\subsection{No Manufacturers' Emission Reduction Investment Model}

4.2.1. Centralized Decision. When the manufacturer does not invest in emission reduction, the government will charge fines of $F_{m}$ on the supply chain. In this case, the total profit function of the supply chain is

$$
\pi_{S C}^{N C}=p_{r}\left(\rho a-p_{r}+r p_{e}\right)+p_{e}\left((1-\rho) a-p_{e}+r p_{r}\right)-F_{m} .
$$

Similar to (3), the Hessian matrix of $\pi_{S C}^{N C}$ with $p_{r}$ and $p_{e}$ is $H^{N C}=\left[\begin{array}{cc}-2 & 2 r \\ 2 r & -2\end{array}\right]$. Because $\left|H_{1}^{N C}\right|=-2<0 \quad$ and $\left|H_{2}^{N C}\right|=4\left(1-r^{2}\right)>0, H^{N C}$ is also a negative definite matrix and there exists a maximum.

From (9), the first-order derivatives of $p_{r}$ and $p_{e}$ are shown as follows: 


$$
\left\{\begin{array}{l}
\frac{\partial \pi_{S C}^{N C}}{\partial p_{r}}=\rho a-2 p_{r}+2 r p_{e}=0 \\
\frac{\partial \pi_{S C}^{N C}}{\partial p_{e}}=(1-\rho) a-2 p_{e}+2 r p_{r}=0
\end{array}\right.
$$

and the optimal retail price and direct sales price can be attained:

$$
\begin{aligned}
& p_{r}^{N C}=\frac{(\rho+r-\rho r) a}{2\left(1-r^{2}\right)}, \\
& p_{e}^{N C}=\frac{(1-\rho+\rho r) a}{2\left(1-r^{2}\right)} .
\end{aligned}
$$

Therefore, the total profit of the supply chain and the utility of the government without emission reduction investment are as follows:

$$
\begin{aligned}
& \pi_{S C}^{N C}=\frac{(1-2 \rho(1-\rho)(1-r)) a^{2}}{4\left(1-r^{2}\right)}-F_{m}, \\
& \pi_{G}^{N C}=\frac{(1-2 \rho(1-\rho)(1-r)) a^{2}}{4\left(1-r^{2}\right)} .
\end{aligned}
$$

4.2.2. Decentralized Decision. If the manufacturer invests nothing in emission reduction, the retailer will bear a certain percentage of fines when they decide separately. When the percentage of fines is $m$, the profit functions of the manufacturer and the retailer are

$$
\begin{aligned}
& \pi_{M}^{N D}=w\left(\rho a-p_{r}+r p_{e}\right)+p_{e}\left((1-\rho) a-p_{e}+r p_{r}\right)-(1-m) F_{m} \\
& \pi_{R}^{N D}=\left(p_{r}-w\right)\left(\rho a-p_{r}+r p_{e}\right)-m F_{m} .
\end{aligned}
$$

Applying the converse approach, at the first stage, the optimal retail price with given wholesale price $w$ can be worked out as follows:

$$
p_{r}^{N D}=\frac{\rho a+w+r p_{e}}{2} .
$$

At the second stage, taking (25) into (28), the optimal wholesale price and direct sales price are

$$
\begin{aligned}
& w^{N D}=\frac{(\rho+(1-\rho) r) a}{2\left(1-r^{2}\right)}, \\
& p_{e}^{N D}=\frac{(1-\rho+\rho r) a}{2\left(1-r^{2}\right)} .
\end{aligned}
$$

Then, the optimal retail price is

$$
p_{r}^{N D}=\frac{(3 \rho+(2(1-\rho)-\rho r) r) a}{4\left(1-r^{2}\right)} .
$$

At last, the optimal profit of the manufacturer is

$$
\pi_{M}^{N D}=\frac{\left(\left(\rho^{2}(3-r)-4 \rho\right)(1-r)+2\right) a^{2}}{8\left(1-r^{2}\right)}-(1-m) F_{m} .
$$

The optimal profit of the retailer is

$$
\pi_{R}^{N D}=\frac{\rho^{2} a^{2}}{16}-m F_{m} .
$$

The optimal profit of the total supply chain is

$\pi_{S C}^{N D}=\frac{\left(\rho^{2}(1-r)(7-r)-8 \rho(1-r)+4\right) a^{2}}{16\left(1-r^{2}\right)}-F_{m}$.

The optimal utility of the government is

$$
\pi_{G}^{N D}=\frac{\left(\rho^{2}(1-r)(7-r)-8 \rho(1-r)+4\right) a^{2}}{16\left(1-r^{2}\right)} .
$$

The profits of the supply chain and government in four models are summarized in Table 2.

\subsection{Model Analysis}

Proposition 1. When companies invest in carbon emissions based on centralized decision modes, proper channel competition can increase the profits of the supply chain and social benefits.

Proof. According to equation (7), $\left(\left(\partial \pi_{S C}^{Y C}\right) / \partial \rho\right)=\left(\left(a^{2}(2 \rho-1)\right) / 2(1+r)\right), \quad$ so when $\rho<0.5$, $\left(\partial \pi_{S C}^{Y C} / \partial \rho\right)<0$ and when $\rho>0.5,\left(\partial \pi_{S C}^{Y C} / \partial \rho\right)>0$, it means that the total profit of the supply chain witnesses a downward trend as the degree of consumer preference for the retail channel is greater and when $\rho$ equals 0.5 it reaches the lowest point, but it begins to rise after that moment. Based on equation (8), $\left(\partial \pi_{G}^{Y C} / \partial \rho\right)=\left(\left(a^{2}(2 \rho-1)\right) /(2(1+r))\right)$, and the same results can be attained in the social benefits.

Proposition 2. When companies invest in carbon emissions based on centralized decision modes, increasing government subsidies is beneficial to the overall benefits of the supply chain but is not conducive to social benefits.

Proof. According to equation $\left(\partial \pi_{S C}^{Y C} / \partial s\right)=\left(\left(\theta a+2 s \theta^{2}(1-r)\right) / 2\right)>0 ;$ meanwhile, based on equation $(8),\left(\partial \pi_{G}^{Y C} / \partial s\right)=-s \theta^{2}(1-r)<0$, so it is obvious that this proposition stands.

Proposition 3. The greater the consumer's preference for retail channels, the higher the price of products in retail channels but the lower the price of products in direct sales channels.

Proof. The supply chain companies formulate their optimal emission reduction levels based on the government's subsidy coefficients $s_{1}$ and $s_{2}$. From (13), the Hessian matrix of $\pi_{M}^{Y D}$ with $w, p_{e}$, and $\theta$ is 


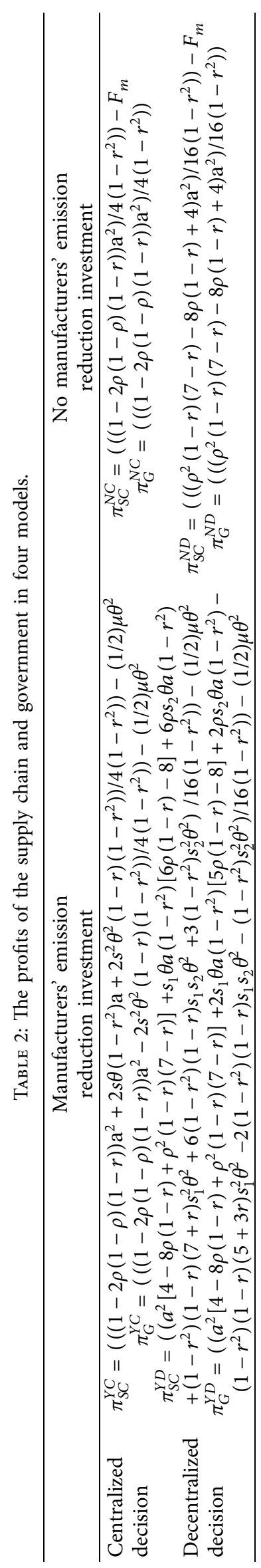




$$
H=\left[\begin{array}{ccc}
-1 & r & \frac{s_{2}}{2}-(1-r) \frac{s_{1}}{2} \\
r & r^{2}-2 & \frac{r s_{2}}{2}-\frac{(1-r)(2+r) s_{1}}{2} \\
\frac{s_{2}}{2}-(1-r) \frac{s_{1}}{2} \frac{r s_{2}}{2}-\frac{(1-r)(2+r) s_{1}}{2} & (1-r) s_{1} s_{2}-(1-\lambda) \mu
\end{array}\right] .
$$

When $s_{1} s_{2}<((1-\lambda) \mu /(1-r))$, $\left(\partial^{2} \pi_{M}^{Y D} / \partial \theta^{2}\right)=(1-r) s_{1} s_{2}-(1-\lambda) \mu<0$, so $\pi_{M}^{Y D}$ is a strictly concave function of $\theta$. As $r^{2}-2<0$, $-\left(r^{2}-2\right)-r^{2}=2\left(1-r^{2}\right)>0$, and $\pi_{M}^{Y D}$ is also a joint concave function with $w$ and $p_{e}$. Because it is uncertain whether $(1-\lambda) \mu-(1-r) s_{1} s_{2}-\left(\left(s_{2} / 2\right)-(1-r)\left(s_{1} / 2\right)\right)^{2}$ is positive or not, $\pi_{M}^{Y D}$ is not a joint concave function with $w$ and $\theta$ and is not a joint concave function with $w, p_{e}$, and $\theta$, which is the reason why the overall optimal results cannot be calculated by the first-order derivative.

However, as $\pi_{M}^{Y D}$ is a joint concave function with $w$ and $p_{e}$, the manufacturers' optimal price can be attained at first with fixed $\theta$, followed by taking it into formula (9) to work out the optimal carbon emissions level. Therefore, the optimal decision-makings of the manufacturer are shown as follows:

$$
\begin{aligned}
\theta^{*} & =\frac{2\left(1-r^{2}\right)(2-\rho+\rho r) a}{8 \mu(1-\lambda) C_{2}-\left(4 r C_{3}+2 C_{2}\left(3-r^{2}\right)\right) s_{1}^{2}-2 C_{3} s_{2}^{2}-4 C_{2}(1-r) s_{1} s_{2}}, \\
p_{r}^{Y D} & =\frac{(3 \rho+(2(1-\rho)-\rho r) r) a-\left(1-r^{2}\right)(1+r) s_{1} \theta^{*}-\left(1-r^{2}\right) s_{2} \theta^{*}}{4\left(1-r^{2}\right)}, \\
w^{Y D} & =\frac{(\rho+(1-\rho) r) a-\left(1-r^{2}\right)\left(s_{1}-s_{2}\right) \theta^{*}}{2\left(1-r^{2}\right)}, \\
p_{e}^{Y D} & =\frac{(1-\rho+\rho r) a-\left(1-r^{2}\right) s_{1} \theta^{*}}{2\left(1-r^{2}\right)} .
\end{aligned}
$$

The level of carbon emissions should be positive, so $\theta^{*}>0$. According to $0<r<1$ and $0<\rho<1$, we can get $8 \mu(1-$ d) $C_{2}-\left(4 r C_{3}+2 C_{2}\left(3-r^{2}\right)\right) s_{1}^{2}-2 C_{3} s_{2}^{2}-4 C_{2}(1-r) s_{1} s_{2}>0$. Denoting that $C_{4}=8 \mu(1-\lambda) C_{2}-\left(4 r C_{3}+2 C_{2}\left(3-r^{2}\right)\right)$ $s_{1}^{2}-2 C_{3} s_{2}^{2}-4 C_{2}(1-r) s_{1} s_{2}>0$, the first-order derivatives of $p_{r}^{Y D}$ and $p_{e}^{Y D}$ with $\rho$ are $\left(\partial p_{r}^{Y D} / \partial \rho\right)=(((3+r) a) /$ $(4(1+r)))+\left(\left(\left(1-r^{2}\right)^{2} s_{1} a\right) / 2 C_{4}\right)+\left(\left(1-r^{2}\right)(1-r) s_{2} a /\right.$ $\left.2 C_{4}\right)>0 \quad$ and $\quad\left(\partial p_{e}^{Y D} / \partial \rho\right)=-(a / 2(1+r))+\left(\left(\left(1-r^{2}\right)\right.\right.$ $\left.\left.(1-r) s_{1} a\right) / C_{4}\right)<0$, which means that the relationship between the price of products in retail channels and consumers' preference for retail channels is positively correlated, while that in direct sales channels is opposite.

Proposition 4. When the supply chain makes decentralized decision-making, the greater the government's low-carbon subsidies to the manufacturer, the lower the retail price, the wholesale price, and the direct sales price; the greater the government's low-carbon subsidies to the retailer, the lower the retail price but the higher the wholesale price. 
Proof. As for the dual-channel supply chains, the optimal prices are as follows:

$$
\begin{aligned}
& p_{r}^{Y D}=\frac{(3 \rho+(2(1-\rho)-\rho r) r) a-\left(1-r^{2}\right)(1+r) s_{1} \theta-\left(1-r^{2}\right) s_{2} \theta}{4\left(1-r^{2}\right)} \\
& w_{D}^{Y D}=\frac{(\rho+(1-\rho) r) a-\left(1-r^{2}\right) s_{1} \theta+\left(1-r^{2}\right) s_{2} \theta}{2\left(1-r^{2}\right)}, \\
& p_{e}^{Y D}=\frac{(1-\rho+\rho r) a-\left(1-r^{2}\right) s_{1} \theta}{2\left(1-r^{2}\right)} .
\end{aligned}
$$

Therefore, we can get

$$
\begin{aligned}
& \frac{\partial p_{r}^{Y D}}{\partial s_{1}}=-\frac{1+r}{4} \theta<0, \\
& \frac{\partial p_{r}^{Y D}}{\partial s_{2}}=-\frac{1}{4} \theta<0, \\
& \frac{\partial w_{D}^{Y D}}{\partial s_{1}}=-\frac{1}{2} \theta<0, \\
& \frac{\partial w_{D}^{Y D}}{\partial s_{2}}=\frac{1}{2} \theta>0, \\
& \frac{\partial p_{e}^{Y D}}{\partial s_{1}}=-\frac{1}{2} \theta<0 .
\end{aligned}
$$

That is, the retail price is negatively correlated with the government's low-carbon subsidy coefficients $s_{1}$ and $s_{2}$ to manufacturers and retailers; the wholesale price is negatively correlated with the government's low-carbon subsidy coefficient $s_{1}$ for the manufacturer but positively correlated with $s_{2}$ for the retailer; the direct sales price in the dualchannel supply chain is negatively correlated with $s_{1}$ for the manufacturer.

Proposition 5. In the case of supply chain companies that invest in emission reductions, for any given $\theta, \rho$, and $r$, in the case of the government's subsidy coefficient $s, s_{1}$ and $s_{2}$ for the emission reduction per unit product satisfy the relationship $s=\sqrt{\left(\left(\rho^{2}\right.\right.} a^{2}-2 s_{1} \theta a\left(5 \rho C_{1}-8\right)-2 \rho s_{2} \theta a+(5+3 r) C_{1} s_{1}^{2} \theta^{2}+$ $\left.\left.2 C_{1} s_{1} s_{2} \theta^{2}+s_{2}^{2} \theta^{2}\right) / 8 C_{1} \theta^{2}\right)$; the government's emission reduction subsidies for centralized and decentralized decisionmaking supply chains achieve the same social benefits.

Proof. $\pi_{G}^{Y C}=\pi_{G}^{Y D}$ is shown as

$$
\begin{aligned}
& \frac{(1-2 \rho(1-\rho)(1-r)) a^{2}-2 s^{2} \theta^{2}(1-r)\left(1-r^{2}\right)}{4\left(1-r^{2}\right)}-\frac{1}{2} \mu \theta^{2} \\
& \left\{\begin{array}{l}
\left(4-8 \rho(1-r)+\rho^{2}(1-r)(7-r)\right) a^{2}+2 s_{1} \theta a\left(1-r^{2}\right)(5 \rho(1-r)-8)+2 \rho s_{2} \theta a \\
\left(1-r^{2}\right)-\left(1-r^{2}\right)(1-r)(3 r+5) s_{1}^{2} \theta^{2}-2\left(1-r^{2}\right)(1-r) s_{1} s_{2} \theta^{2}-\left(1-r^{2}\right) s_{2}^{2} \theta^{2}
\end{array}\right\} \\
& =\frac{1}{2} \mu \theta^{2} .
\end{aligned}
$$

Then

$$
s=\sqrt{\frac{\rho^{2} a^{2}-2 s_{1} \theta a\left(5 \rho C_{1}-8\right)-2 \rho s_{2} \theta a+(5+3 r) C_{1} s_{1}^{2} \theta^{2}+2 C_{1} s_{1} s_{2} \theta^{2}+s_{2}^{1} \theta^{2}}{8 C_{1} \theta^{2}}},
$$


is attained, where $C_{1}=1-r$. It means that when the government's low-carbon subsidy coefficient of the supply chain under different decision-making situations meets the above formula with the same emission reduction level, the social benefits obtained are the same.

Proposition 6. In the case of supply chain companies that do not invest in emission reductions, the government can obtain higher social benefits by imposing fines on the centralized decision-making supply chain compared with the other supply chain model.

Proof. The utilities of the government in the centralized decision-making and the decentralized decision-making are $\pi_{G}^{N C}=\left(\left((1-2 \rho \quad(1-\rho)(1-r)) a^{2}\right) /\left(4\left(1-r^{2}\right)\right)\right)$ and $\pi_{G}^{N D}$ $=\left(\left(\left(\rho^{2}(1-r)(7-r)-8(1-r)+4\right) a^{2}\right) /\left(16\left(1-r^{2}\right)\right)\right)$, respectively. The difference between them is $\pi_{G}^{N C}-$

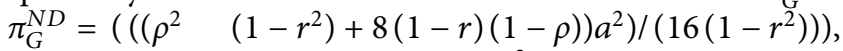
where $0<r<1$ and $0<\rho<1$, so $1-r^{2}>0$ and $1-\rho>0$; then $\pi_{G}^{N C}-\pi_{G}^{N D}>0$ always stands up. In other words, when companies do not invest in emission reduction, the government will obtain higher social benefits by imposing fines on centralized supply chains.

Proposition 7. The supply chain can achieve coordination through low-carbon subsidies and fines in the whole supply chain with the same level of emission reduction.

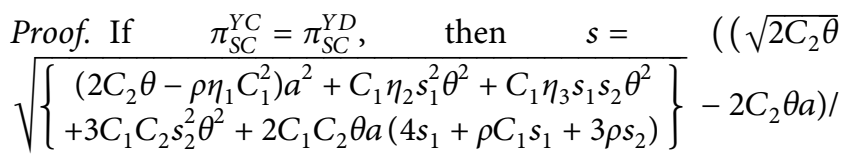
$\left.\left(4 C_{1} C_{2} \theta a\right)\right)$, where $C_{2}=1-r^{2}, C_{3}=1+r^{2}, \eta_{1}=1+7 \rho-\rho r$, $\eta_{2}=\left(1-r^{2}\right)(1-r)(7+r)$, and $\eta_{3}=6\left(1-r^{2}\right)(1-r)$. It means that when the government's low-carbon subsidy coefficient of the supply chain meets the above formula with any given emission reduction level, the entire supply chain is coordinating with the same profits in different decisionmaking cases.

If $\pi_{S C}^{N C}=\pi_{S C}^{N D}$ or $\left(\left((1-2 \rho(1-\rho)(1-r)) a^{2}\right) /\left(4\left(1-r^{2}\right)\right)\right)-$ $F_{m}^{C}=\left(\left(\left(\rho^{2}(1-r)(7-r)-8 \rho(1-r)+4\right) a^{2}\right) / 16\left(1-r^{2}\right)\right)-F_{m}^{D}$, the relationship between $F_{m}^{C}$ and $F_{m}^{D}$ is $F_{m}^{C}=F_{m}^{D}+(\stackrel{m}{(\rho}$ $\left.\left.\left(8 r+\rho r^{2}-7 \rho\right)\right) /\left(16\left(1-r^{2}\right)\right)\right)$, which presents that when the fines meet the above formula with any given emission reduction level, the entire supply chain can achieve coordination in different decision-making cases.

\section{Numerical Experiments}

5.1. Centralized Decision. For a centralized supply chain, the optimal emission reduction level is obtained according to formula (7): $\theta^{Y C}=\left(s a /\left(2 \mu-2(1-r) s^{2}\right)\right)$. In centralized decision-making mode, assuming that $a=100, \mu=300$, $\lambda=0.3, r=0.6, s=2$, and $\theta=0.34$, the impacts of $\rho$ on the prices and profits are shown in Table 3 and Figure 2.

It can be seen that when consumers prefer the retail channel, the retail price increases, while the direct sales price decreases; at the same time, the relationship between the profit of the supply chain or the government and consumers' preference for retail channels shows U-shape trends, which means that the overall profit of the supply chain and the government utility both see a decreasing trend firstly and then an increasing trend. When $\rho=0.5$, which means that the retail channel and the direct sales channel share the equal market, the retail price is the same as the direct sales price, and the overall profit of the supply chain and the government utility reach the lowest point. Therefore, when the competition among supply chain companies is stronger, the utility of all members will be higher under the same conditions.

Table 4 and Figure 3 show the effect of the government's subsidy coefficient $s$ on prices and profits. As we can see directly in Figure 3, giving subsidies to supply chain members can reduce the prices in different sales channels. The reason is that subsidies can cut down the cost of products paid by companies themselves, so the more subsidies are, the lower prices are, not only for the retail price but also for the direct sales price. Obviously, the total profit of the supply chain increases as prices reduce. However, government subsidies will increase fiscal expenditures, so it is not conducive to the improvement of the overall social benefits.

5.2. Decentralized Decision. For a decentralized supply chain, the optimal emission reduction level is $\theta^{*}$, assuming that $a=100, \mu=300, \lambda=0.3, r=0.6, \theta=0.34, s_{1}=1.5$, and $s_{2}=1$, and the impacts of $\rho$ on prices $\left(p_{r}^{Y D}, p_{e}^{Y D}, w\right)$ and profits $\left(\pi_{M}^{Y D}, \pi_{R}^{Y D}, \pi_{S C}^{Y D}, \pi_{G}^{Y D}\right)$ in the supply chain are shown in Table 5. Figures 4 and 5 show the effects of $\rho$ on prices and profits, respectively. As consumers prefer the retail channel, the retail price and wholesale price increase, while the direct sales price decreases. It can be explained that when the demand of retail channel is rising, the price in this channel is also climbing, but the demand of alternative channel and the price is reducing; and, in Figure 5, the manufacturer and the retailer see totally different trend as $\rho$ is rising. On the contrary, as shown in this figure, the profit of the total supply chain and the utility of the government change consistently, and they will meet the lowest point when $\rho=0.6$. In order to ensure that the retailer wholesales products from the manufacturer, it must be $p_{e}^{Y D}>w$. Only in this way can the retail channel be effective. It can be seen from Table 5 that when $\rho<0.4$ with given $s_{1}=1.5$ and $s_{2}=1$, the dual-channel supply chain is effective. Therefore, in decentralized decision modes, the degree of consumer preference for the retail channel is only of benefit to the retailer.

Assuming that $\rho=0.4, a=100, \mu=300, \lambda=0.3, r=0.6$, and $\theta=0.34$, the impacts of $s_{1}$ and $s_{2}$ on the supply chain and the government utility are shown in Table 6 and more specific changes can be seen from Figures 6-9. When the government's low-carbon subsidy coefficient for retailers is fixed, every price is lower when the government gives more subsidies to the manufacturer; and the higher low-carbon 
TABLE 3: The effect of the degree of consumer preference for the retail channel $\rho$ based on centralized decision.

\begin{tabular}{lccccc}
\hline No. & $\rho$ & $p_{r}^{Y C}$ & $p_{e}^{Y C}$ & $\pi_{S C}^{Y C}$ & 3641.75 \\
\hline 1 & 0.1 & 49.66 & 74.66 & 3423.00 & 3607.57 \\
2 & 0.2 & 52.79 & 71.54 & 3266.75 & 3388.82 \\
3 & 0.3 & 55.91 & 68.41 & 3173.00 & 3232.57 \\
4 & 0.4 & 69.04 & 65.29 & 3141.75 & 3138.82 \\
5 & 0.5 & 65.29 & 62.16 & 3173.00 & 3107.57 \\
6 & 0.6 & 68.41 & 59.04 & 3266.75 & 3232.82 \\
7 & 0.7 & 71.54 & 52.79 & 3423.00 & 3388.82 \\
8 & 0.8 & 74.66 & 49.66 & 3641.75 \\
9
\end{tabular}

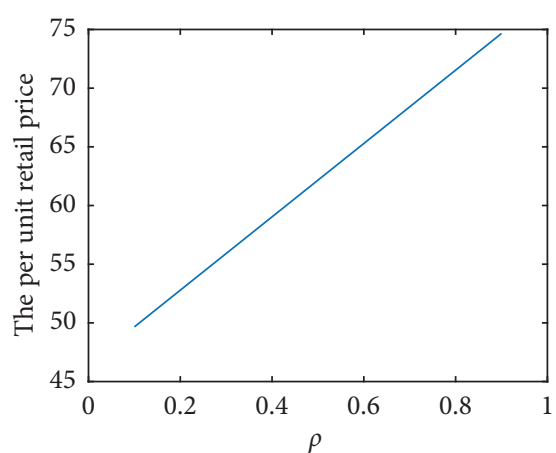

(a)

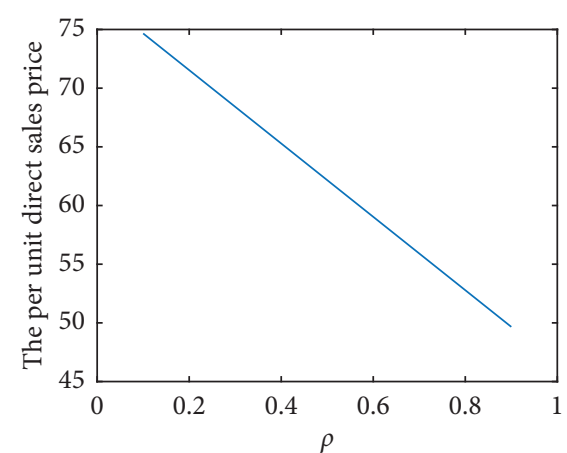

(b)

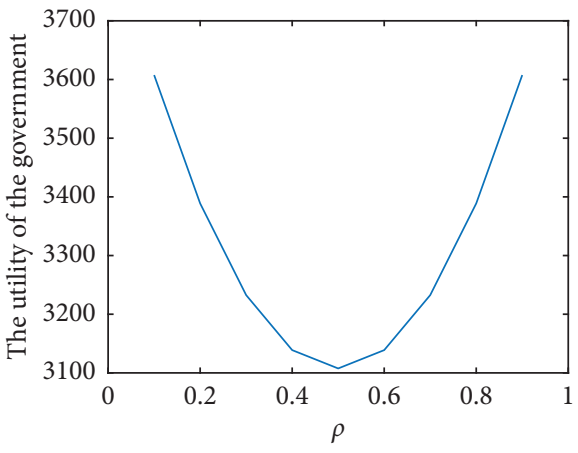

(d)

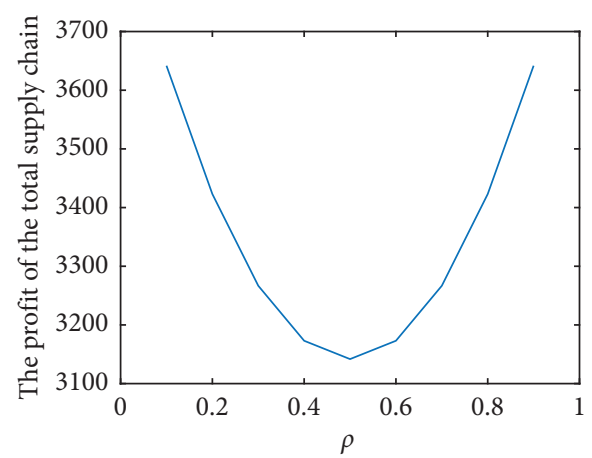

(c)

Figure 2: The effect of the degree of consumer preference for the retail channel $\rho$ based on centralized decision.

TABLE 4: The effect of the government's subsidy coefficient $s$ based on centralized decision.

\begin{tabular}{|c|c|c|c|c|c|}
\hline No. & $s$ & $p_{r}^{Y C}$ & $p_{e}^{Y C}$ & $\pi_{S C}^{Y C}$ & $\pi_{G}^{Y C}$ \\
\hline 1 & 0.5 & 59.29 & 65.54 & 3147.42 & 3138.90 \\
\hline 2 & 1.0 & 59.21 & 65.46 & 3155.93 & 3138.89 \\
\hline 3 & 1.5 & 59.12 & 65.37 & 3164.46 & 3138.86 \\
\hline 4 & 2.0 & 59.04 & 65.29 & 3173.00 & 3138.82 \\
\hline 5 & 2.5 & 58.95 & 65.20 & 3181.55 & 3138.77 \\
\hline
\end{tabular}

subsidy coefficient for the manufacturer, the higher profits of the retailer but the lower profits of the manufacturer, the whole supply chain, and the government. It means that more subsidies to the manufacturer can weaken supply chain and social benefits. On the other hand, it can be seen that when the government's low-carbon subsidy coefficient to the manufacturer is constant, increasing it to the retailer will increase the wholesale price as well as the profits of all supply chain members and social benefits. Therefore, the government needs to reasonably decide the scope of subsidies for the manufacturer and the retailer to encourage emission reduction investment and increase social benefits as a result. 


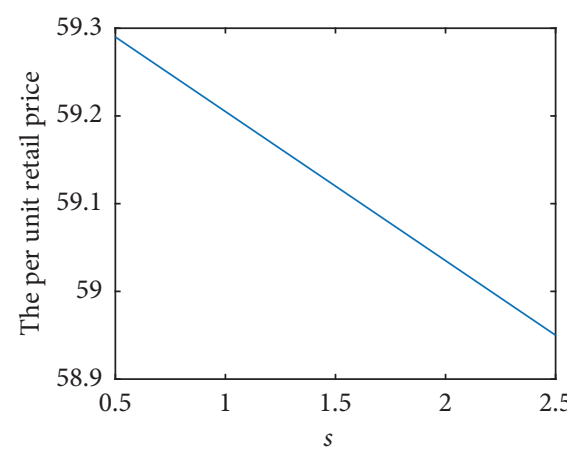

(a)

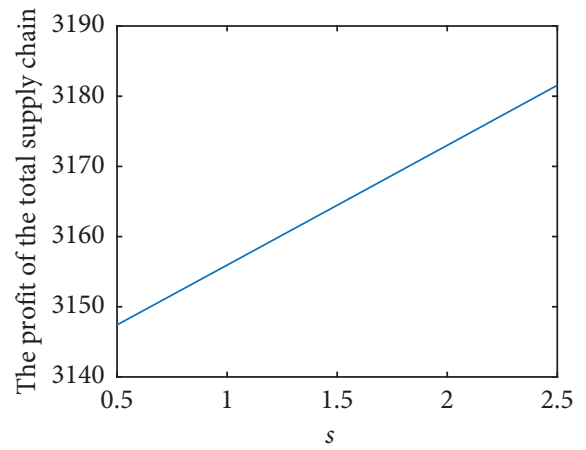

(c)

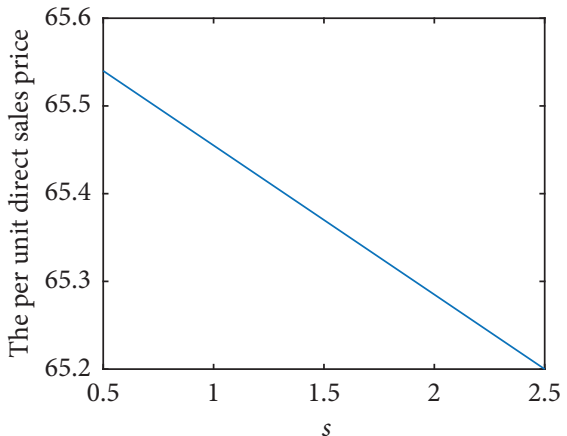

(b)

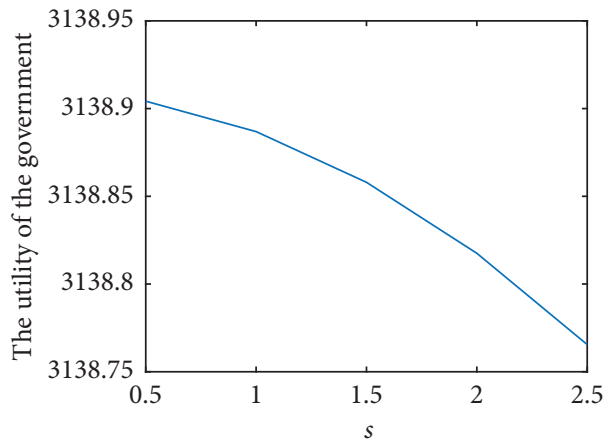

(d)

FIgURE 3: The effect of the government's subsidy coefficient $s$ based on centralized decision.

TABLE 5: The effect of the degree of consumer preference for the retail channel $\rho$ based on decentralized decision.

\begin{tabular}{|c|c|c|c|c|c|c|c|c|}
\hline No. & $\rho$ & $p_{r}^{Y D}$ & $p_{e}^{Y D}$ & $\mathrm{w}$ & $\pi_{M}^{Y D}$ & $\pi_{R}^{Y D}$ & $\pi_{S C}^{Y D}$ & $\pi_{G}^{Y D}$ \\
\hline 1 & 0.1 & 28.77 & 74.75 & 49.92 & 3576.30 & 1.75 & 3578.05 & 3552.05 \\
\hline 2 & 0.2 & 39.09 & 71.62 & 53.04 & 3321.41 & 21.18 & 3342.59 & 3316.25 \\
\hline 3 & 0.3 & 49.40 & 68.50 & 56.17 & 3104.02 & 53.11 & 3157.13 & 3130.45 \\
\hline 4 & 0.4 & 59.71 & 65.37 & 59.29 & 2924.13 & 97.54 & 3021.67 & 2994.65 \\
\hline 5 & 0.5 & 70.02 & 62.25 & 62.42 & 2781.74 & 154.47 & 2936.21 & 2908.85 \\
\hline 6 & 0.6 & 80.34 & 59.12 & 65.54 & 2676.85 & 223.90 & 2900.75 & 2873.05 \\
\hline 7 & 0.7 & 90.65 & 56.00 & 68.67 & 2609.46 & 305.83 & 2915.29 & 2887.25 \\
\hline 8 & 0.8 & 100.96 & 52.87 & 71.79 & 2579.57 & 400.26 & 2979.83 & 2951.45 \\
\hline 9 & 0.9 & 111.27 & 49.75 & 74.92 & 2587.18 & 507.19 & 3094.37 & 3065.65 \\
\hline
\end{tabular}

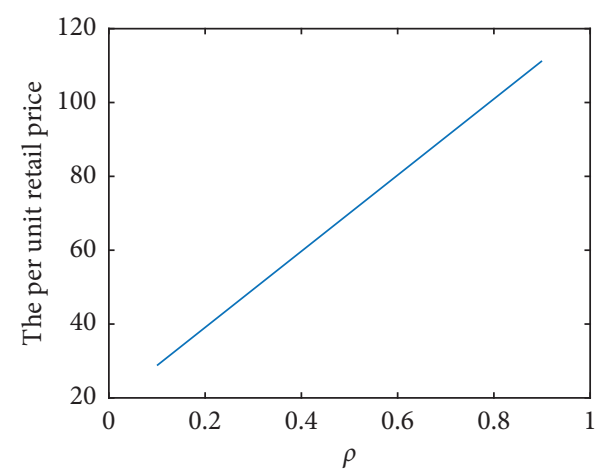

(a)

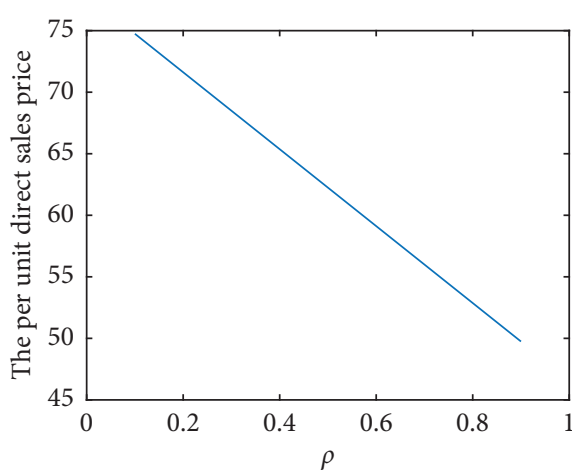

(b)

FIgURe 4: Continued. 


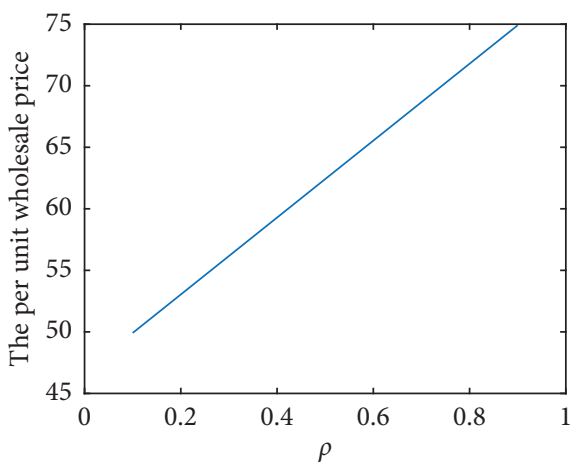

(c)

FIGURE 4: The effect of the degree of consumer preference for the retail channel $\rho$ on prices based on decentralized decision.

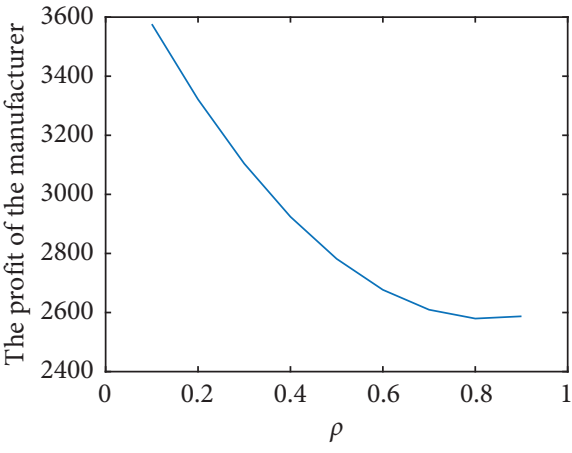

(a)

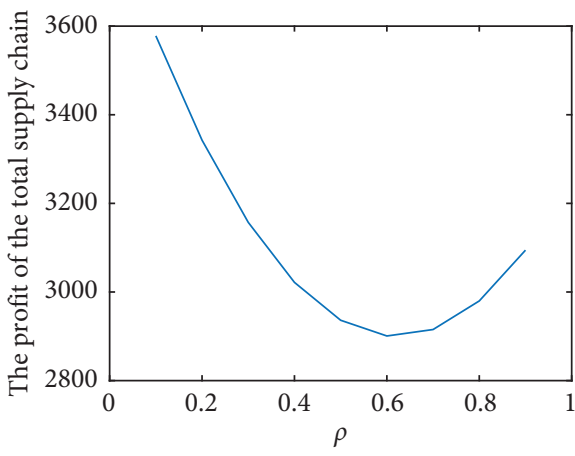

(c)

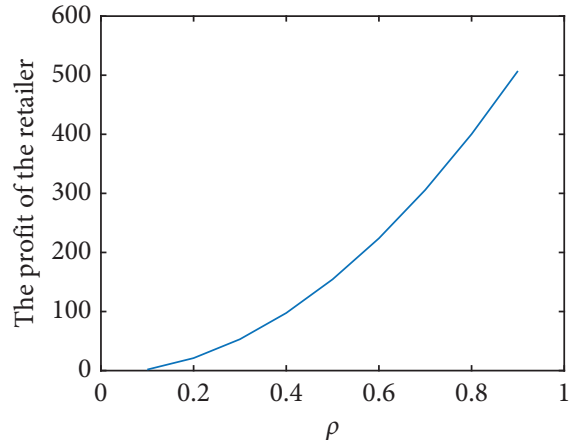

(b)

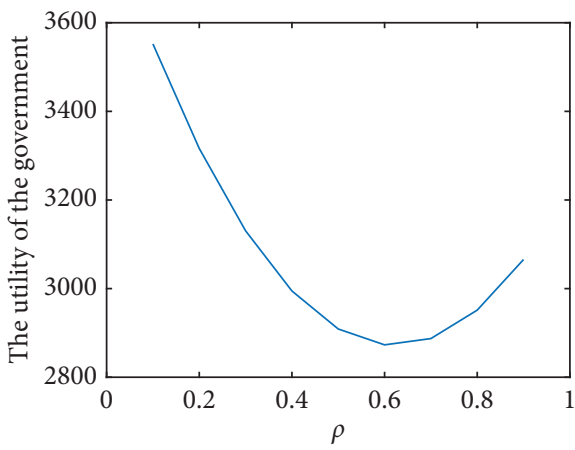

(d)

Figure 5: The effect of the degree of consumer preference for the retail channel $\rho$ on profits based on decentralized decision.

TABLE 6: The effect of the government's subsidy coefficient $s_{1}$ and $s_{2}$ based on decentralized decision.

\begin{tabular}{lccccccccc}
\hline No. & $s_{1}$ & $s_{2}$ & $p_{r}^{Y D}$ & $p_{e}^{Y D}$ & $\mathrm{w}$ & $\pi_{M}^{Y D}$ & $\pi_{R}^{Y D}$ & $\pi_{S C}^{Y D}$ \\
\hline 1 & 0.5 & 1 & 59.85 & 65.54 & 59.46 & 2939.72 & 96.85 & 3036.57 \\
2 & 1 & 1 & 59.78 & 65.46 & 59.38 & 2931.92 & 97.19 & 3029.11 & 3025.29 \\
3 & 1.5 & 1 & 59.71 & 65.37 & 59.29 & 2924.13 & 97.54 & 3021.67 & 2994.65 \\
4 & 2 & 1 & 59.64 & 65.29 & 59.21 & 2916.35 & 97.88 & 3014.23 & 2979.31 \\
5 & 2.5 & 1 & 59.58 & 65.20 & 59.12 & 2908.59 & 98.23 & 3006.81 & 2963.97 \\
6 & 1.5 & 0.5 & 59.75 & 65.37 & 59.21 & 2922.41 & 96.68 & 3019.09 & 2993.81 \\
7 & 1.5 & 1 & 59.71 & 65.37 & 59.29 & 2924.13 & 97.54 & 3021.67 & 2994.65 \\
8 & 1.5 & 1.5 & 59.67 & 65.37 & 59.38 & 2925.86 & 98.40 & 3024.26 \\
9 & 1.5 & 2 & 59.63 & 65.37 & 59.46 & 2927.59 & 99.27 & 3026.86 & 2995.49 \\
10 & 1.5 & 2.5 & 59.58 & 65.37 & 59.55 & 2929.33 & 100.14 & 3029.47 & 2997.15 \\
\hline
\end{tabular}




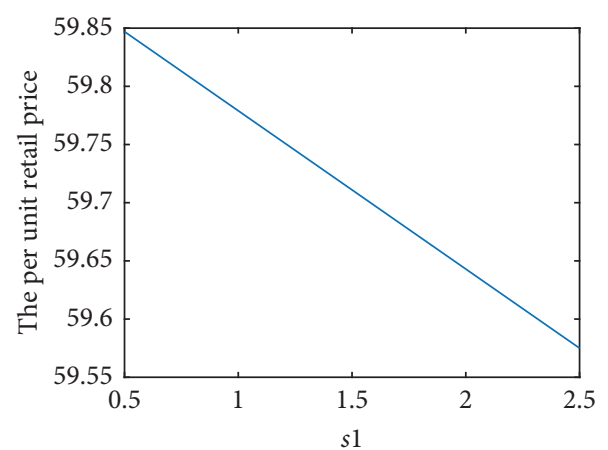

(a)

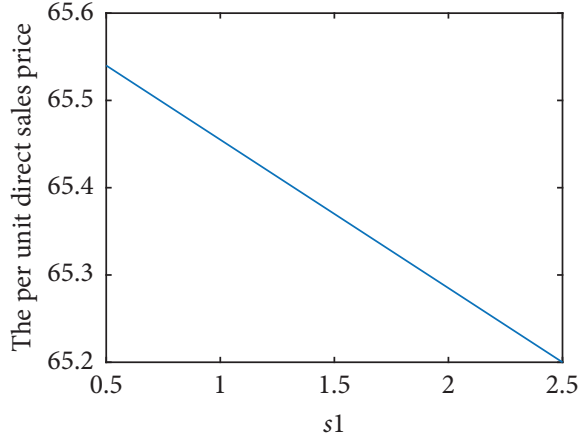

(b)

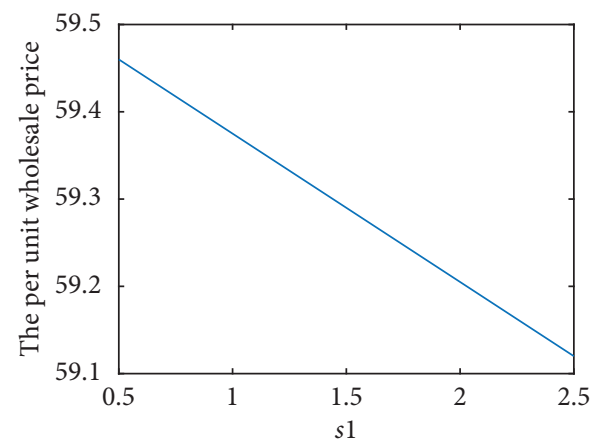

(c)

Figure 6: The effect of the government's subsidy coefficient to the manufacturer $s_{1}$ on prices and profits based on decentralized decision.

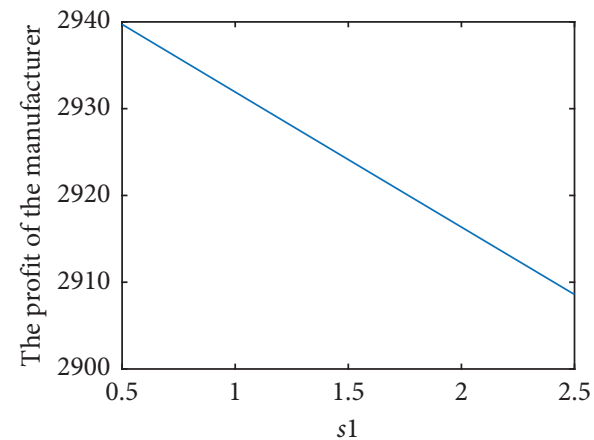

(a)

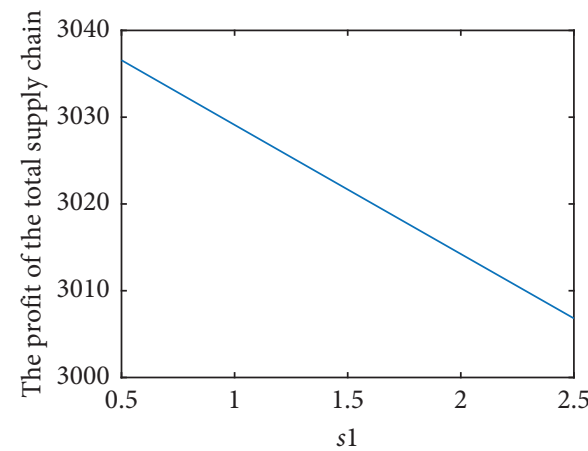

(c)

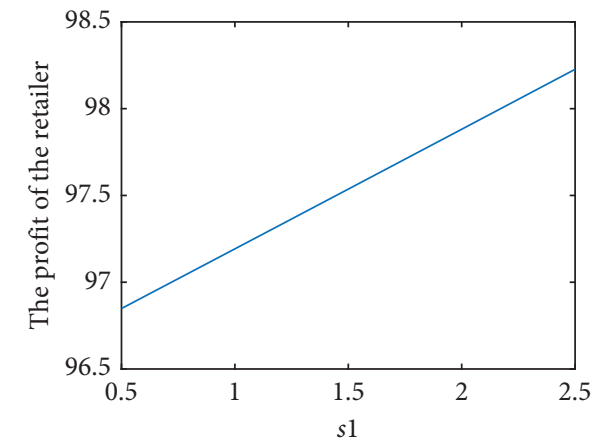

(b)

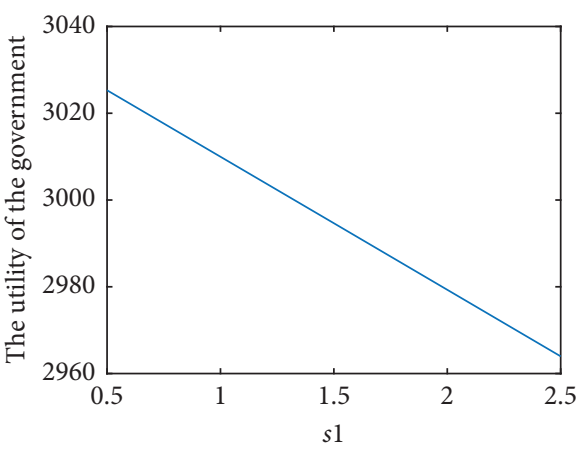

(d)

FIGURE 7: The effect of the government's subsidy coefficient to the manufacturer $s_{1}$ on profits based on decentralized decision. 


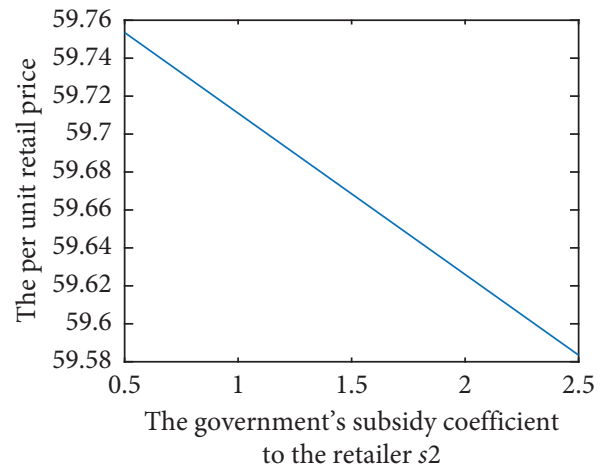

(a)

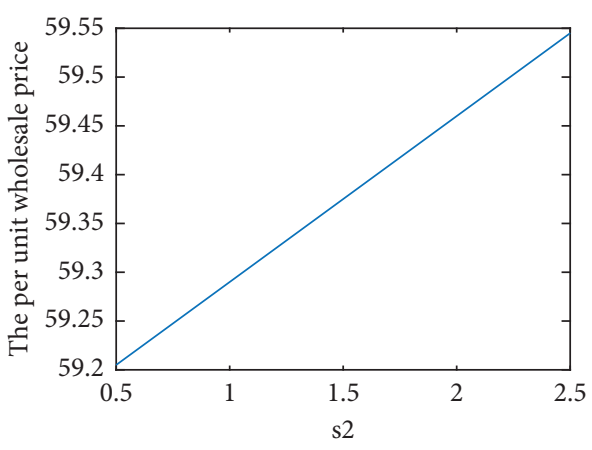

(b)

Figure 8: The effect of the government's subsidy coefficient to the retailer $s_{2}$ on prices based on decentralized decision.

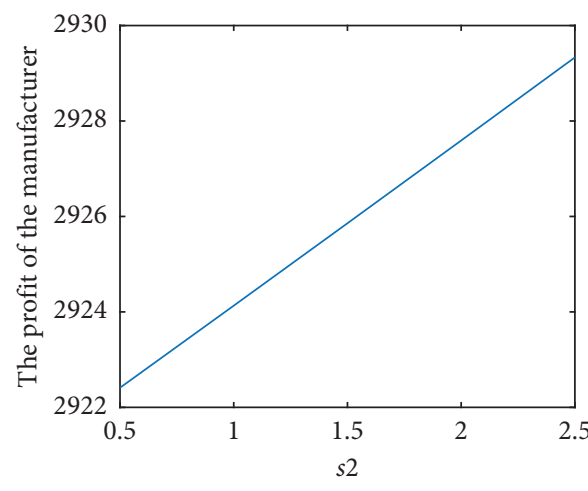

(a)

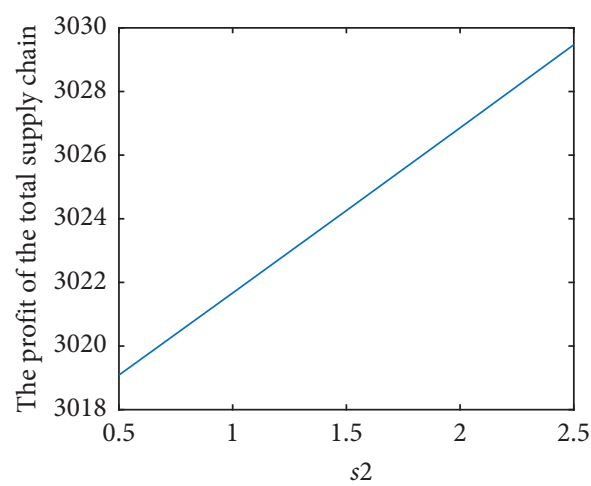

(c)

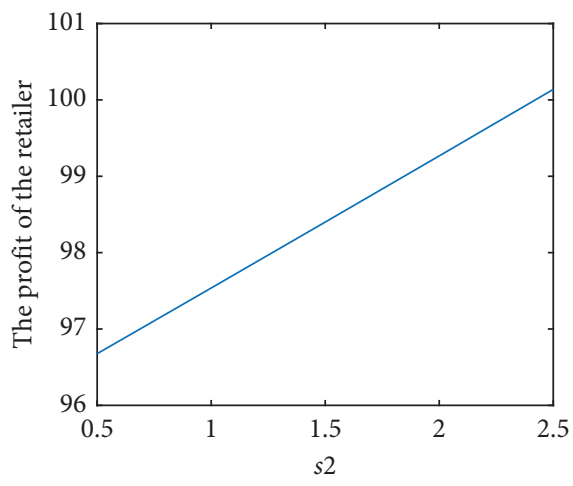

(b)

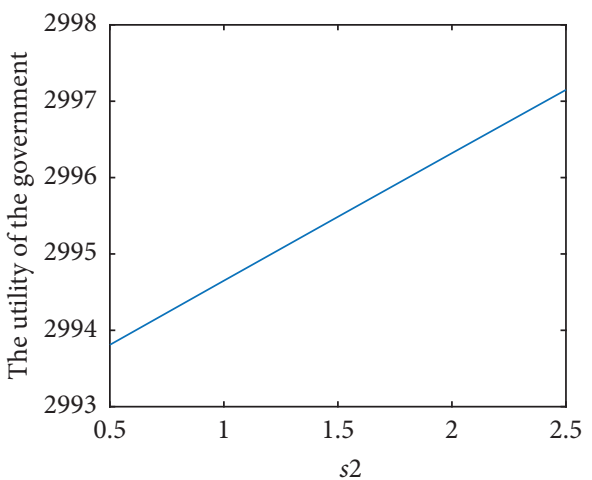

(d)

FIGURE 9: The effect of the government's subsidy coefficient to the retailer $s_{2}$ on profits based on decentralized decision.

\section{Conclusions}

Considering consumers' channel preferences and supply chain members' behavior, this paper constructs a game model led by manufacturer to study what the government should do when manufacturers invest in emission reductions or not in a dual-channel supply chain; and the supply chain members adopt a centralized or decentralized decision-making model. Based on this model, this paper introduces the consumers' channel preference coefficient and the government subsidy coefficient to analyze how they affect the supply chain and government benefits and aims to guide the government to take incentive or penalties measures to encourage supply chain members to reduce carbon emissions. The main results are summarized as follows:

(1) When manufacturers invest in carbon emissions reduction, for centralized decision-making model, this study found that the government is supposed to take incentive measures in order to maximize supply chain profits, but the cost is the decrease of social benefits. As for consumers channel preference, no matter which sales channel they prefer, it is beneficial 
to improve the overall supply chain and social benefits at the same time.

(2) In decentralized decision-making model when manufacturers invest in reducing carbon emissions, the government adopts incentive measures with lowcarbon subsidies for retailers to be able to increase the profits of all supply chain members and social benefits. However, low-carbon subsidies for manufacturers and the degree of consumer preference for the retail channel only increase the profits of the retailer.

(3) When manufacturers do not take low-carbon investments, compared with centralized and decentralized decision-making supply chain, the government can obtain higher social benefits by imposing fines on the former one.

Based on the results of this paper, some government implications can be attained as follows. First, the government should reasonably plan subsidy policies for supply chain members and appropriately increase the proportion of subsidies to retailers, which will help supply chain members and the government achieve a win-win result. Second, when the supply chain does not invest in reducing carbon emissions, it is better for the government to issue the penalties of entire industrial regarding supply chain members as a whole, so the government should guide the formulation of industry's low-carbon standards. Third, based on fully respecting the laws of the market, the government can regulate market low-carbon behavior of manufacturers and retailers by guiding market expectations, stimulating market vitality, and clarifying investment directions, which is beneficial for them to compete healthily, because good market competition is conducive to the supply chain profits and government utility.

Our research has some limitations and further research can be done at least in the following aspects. First, this article explored incentive measures represented by low-carbon subsidies and punitive measures represented by fines. Other governmental measures such as carbon taxes and carbon trade are also worth studying in further research. Second, this article studied a simple two-echelon supply chain with one manufacturer and one retailer. Actually, a supply chain is likely to include multiple manufacturers and multiple retailers, so multiple supply chain members can be considered in the future.

\section{Conflicts of Interest}

The authors declare that there are no conflicts of interest regarding the publication of this paper.

\section{Acknowledgments}

This work was supported by the National Natural Science Foundation of China (no.71804189) and the Fundamental Research Funds for the Central Universities (no. 19XCX040B).

\section{References}

[1] P. Wu, Y. Jin, Y. Shi, and H. Shyu, "The impact of carbon emission costs on manufacturers' production and location decision," International Journal of Production Economics, vol. 193, pp. 193-206, 2017.

[2] M. Hariga, R. As'ad, and A. Shamayleh, "Integrated economic and environmental models for a multi stage cold supply chain under carbon tax regulation," Journal of Cleaner Production, vol. 166, pp. 1357-1371, 2017.

[3] Y. Yuyin and L. Jinxi, "The effect of governmental policies of carbon taxes and energy-saving subsidies on enterprise decisions in a two-echelon supply chain," Journal of Cleaner Production, vol. 181, pp. 675-691, 2018.

[4] China's State Council, Enhanced Actions on Climate Change: China's Intended Nationally Determined, China's State Council, Beijing, China, 2015.

[5] D. Ghosh and J. Shah, "Supply chain analysis under green sensitive consumer demand and cost sharing contract," International Journal of Production Economics, vol. 164, pp. 319-329, 2015.

[6] S. Du, L. Zhu, L. Liang, and F. Ma, "Emission-dependent supply chain and environment-policy-making in the "capand-trade" system," Energy Policy, vol. 57, pp. 61-67, 2013.

[7] L. Xu, C. Wang, and J. Zhao, "Decision and coordination in the dual-channel supply chain considering cap-and-trade regulation," Journal of Cleaner Production, vol. 197, pp. 551561, 2018.

[8] X. Chen, H. Zhang, M. Zhang, and J. Chen, "Optimal decisions in a retailer Stackelberg supply chain," International Journal of Production Economics, vol. 187, pp. 260-270, 2017.

[9] Y. C. Chen, S.-C. Fang, and U.-P. Wen, "Pricing policies for substitutable products in a supply chain with Internet and traditional channels," European Journal of Operational Research, vol. 224, no. 3, pp. 542-551, 2013.

[10] X. Qian, F. T. S. Chan, J. Zhang, M. Yin, and Q. Zhang, "Channel coordination of a two-echelon sustainable supply chain with a fair-minded retailer under cap-and-trade regulation," Journal of Cleaner Production, vol. 244, Article ID 118715, 2020.

[11] A. Ranjan and J. K. Jha, "Pricing and coordination strategies of a dual-channel supply chain considering green quality and sales effort," Journal of Cleaner Production, vol. 218, pp. 409-424, 2019.

[12] C. Wang, W. Wang, and R. Huang, "Supply chain enterprise operations and government carbon tax decisions considering carbon emissions," Journal of Cleaner Production, vol. 152, pp. 271-280, 2017.

[13] L. Xu, S. Cho, and S.-H. Lee, "Emission tax and optimal privatization in Cournot-Bertrand comparison," Economic Modelling, vol. 55, pp. 73-82, 2016.

[14] A. Barman, R. Das, and P. Kanti De, "Optimal pricing and greening decision in a manufacturer retailer dual-channel supply chain," Materials Today: Proceedings, vol. 42, pp. 870-875, 2021.

[15] C. Zhang, Y. Liu, and G. Han, "Two-stage pricing strategies of a dual-channel supply chain considering public green preference," Computers \& Industrial Engineering, vol. 151, Article ID 106988, 2021.

[16] Y. Zhou, J. Feng, J. Wei, and X. Sun, "Pricing decisions of a dual-channel supply chain considering supply disruption risk," Discrete Dynamics in Nature and Society, vol. 2018, Article ID 6841519, 16 pages, 2018. 
[17] B. Li, M. Zhu, Y. Jiang, and Z. Li, "Pricing policies of a competitive dual-channel green supply chain," Journal of Cleaner Production, vol. 112, pp. 2029-2042, 2016.

[18] J. Xu, Q. Qi, and Q. Bai, “Coordinating a dual-channel supply chain with price discount contracts under carbon emission capacity regulation," Applied Mathematical Modelling, vol. 56, pp. 449-468, 2018.

[19] G. Cai, Z. G. Zhang, and M. Zhang, "Game theoretical perspectives on dual-channel supply chain competition with price discounts and pricing schemes," International Journal of Production Economics, vol. 117, no. 1, pp. 80-96, 2009.

[20] Q. H. Xie and P. Q. Huang, "A quantity discount model for coordination of internet-based hybrid channels," Systems Enginering Theory \& Practice, vol. 27, no. 8, pp. 1-11, 2007.

[21] A. David and E. Adida, "Competition and coordination in a two-channel supply chain," Production and Operations Management, vol. 24, no. 8, pp. 1358-1370, 2015.

[22] G. Xu, B. Dan, X. Zhang, and C. Liu, "Coordinating a dualchannel supply chain with risk-averse under a two-way revenue sharing contract," International Journal of Production Economics, vol. 147, pp. 171-179, 2014.

[23] Z. P. Ding and Y. Z. Liu, "Revenue sharing contract in dual channel supply chain in case of fre riding," Journal of Systems Enginering, vol. 28, no. 3, pp. 459-469, 2013.

[24] Y. Zhou, M. Bao, X. Chen, and X. Xu, "Co-op advertising and emission reduction cost sharing contracts and coordination in low-carbon supply chain based on fairness concerns," Journal of Cleaner Production, vol. 133, pp. 402-413, 2016.

[25] P. He, Y. He, C. Shi, H. Xu, and L. Zhou, "Cost-sharing contract design in a low-carbon service supply chain," Computers \& Industrial Engineering, vol. 139, Article ID 106160, 2020.

[26] S.-M. Hosseini-Motlagh, K. Govindan, M. Nematollahi, and A. Jokar, "An adjustable bi-level wholesale price contract for coordinating a supply chain under scenario-based stochastic demand," International Journal of Production Economics, vol. 214, pp. 175-195, 2019.

[27] R. Du, A. Banerjee, and S.-L. Kim, "Coordination of twoechelon supply chains using wholesale price discount and credit option," International Journal of Production Economics, vol. 143 , no. 2 , pp. $327-334,2013$.

[28] Q. Peng, C. Wang, and L. Xu, "Emission abatement and procurement strategies in a low-carbon supply chain with option contracts under stochastic demand," Computers \& Industrial Engineering, vol. 144, Article ID 106502, 2020.

[29] H. Zhao, S. Song, Y. Zhang, Y. Liao, and F. Yue, "Optimal decisions in supply chains with a call option contract under the carbon emissions tax regulation," Journal of Cleaner Production, vol. 271, Article ID 122199, 2020.

[30] G. H. Chao, S. M. R. Iravani, and R. C. Savaskan, "Quality improvement incentives and product recall cost sharing contracts," Management Science, vol. 55, no. 7, pp. 1122-1138, 2009.

[31] Z. Wang, A. E. I. Brownlee, and Q. Wu, "Production and joint emission reduction decisions based on two-way cost-sharing contract under cap-and-trade regulation," Computers \& Industrial Engineering, vol. 146, Article ID 106549, 2020.

[32] B. Sarkar, B. Ganguly, M. Sarkar, and S. Pareek, "Effect of variable transportation and carbon emission in a three-echelon supply chain model," Transportation Research Part E: Logistics and Transportation Review, vol. 91, pp. 112-128, 2016.

[33] H. Li, C. Wang, M. Shang, and W. Ou, "Pricing, carbon emission reduction, low-carbon promotion and returning decision in a closed-loop supply chain under vertical and horizontal cooperation," International Journal of Environmental Research and Public Health, vol. 14, no. 11, Article ID 1332, 2017.

[34] S. M. Aljazzar, A. Gurtu, and M. Y. Jaber, "Delay-in-payments - a strategy to reduce carbon emissions from supply chains," Journal of Cleaner Production, vol. 170, pp. 636-644, 2018.

[35] D. Wang, "Dynamic optimization of supply chain cooperation and low-carbon publicity under government rewards and punishments," Operations Research and Management Science, vol. 29, no. 4, pp. 113-120, 2020.

[36] X. Wang and S. Han, "Optimal operation and subsidies/ penalties strategies of a multi-period hybrid system with uncertain return under cap-and-trade policy," Computers \& Industrial Engineering, vol. 150, Article ID 106892, 2020.

[37] X. Chen and G. Hao, "Sustainable pricing and production policies for two competing firms with carbon emissions tax," International Journal of Production Research, vol. 53, no. 21, pp. 6408-6420, 2015.

[38] X. Chen, S. Benjaafar, and A. Elomri, "The carbon-constrained EOQ," Operations Research Letters, vol. 41, no. 2, pp. 172-179, 2013.

[39] C.-H. Wu, "A dynamic perspective of government intervention in a competitive closed-loop supply chain," European Journal of Operational Research, vol. 294, no. 1, pp. 122-137, 2021.

[40] G. Zhang, P. Cheng, H. Sun, Y. Shi, G. Zhang, and A. Kadiane, "Carbon reduction decisions under progressive carbon tax regulations: a new dual-channel supply chain network equilibrium model," Sustainable Production and Consumption, vol. 27, pp. 1077-1092, 2021.

[41] Y. Zhang and B. Hezarkhani, "Competition in dual-channel supply chains: the manufacturers' channel selection," European Journal of Operational Research, vol. 291, no. 1, pp. 244-262, 2021.

[42] Y. Tian, J. Ma, L. Xie, T. Koivumäki, and V. Seppänen, "Coordination and control of multi-channel supply chain driven by consumers' channel preference and sales effort," Chaos, Solitons \& Fractals, vol. 132, Article ID 109576, 2020.

[43] Q. Meng, M. Li, W. Liu, Z. Li, and J. Zhang, "Pricing policies of dual-channel green supply chain: considering government subsidies and consumers' dual preferences," Sustainable Production and Consumption, vol. 26, pp. 1021-1030, 2021.

[44] J. Beath, D. Ulph, and O. B. Univ, "Cooperative and noncooperative $\mathrm{R}$ and $\mathrm{D}$ in duopoly with spillovers a comment," My Science Work, 1989. 